\title{
Música envejecida y retorno a la libertad. Las críticas a la Escuela de Darmstadt de T. W. Adorno y su propuesta de una "musique informelle"
}

\author{
Aged new music and the return to freedom. Adorno's critiques to \\ Darmstadt School and his proposal of a "musique informelle"
}

Sol Bidon-Chanal

solbidonchanal@gmail.com

(Universidad de San Martín, Buenos Aires, Argentina)

\begin{abstract}
Resumen: Este trabajo se propone reponer y analizar las críticas que Theodor W. Adorno dirige a las composiciones y los procedimientos compositivos de la Escuela de Darmstadt en tanto profundización de ciertas tendencias del dodecafonismo, para posteriormente abordar la propuesta de Adorno de una música informal, considerándola como un contrapunto y una superación respecto de estos desarrollos musicales y encauzándola, a su vez, con el ideal de libertad que le confiere al atonalismo libre así como con el trabajo sobre el material musical que postula para los estilos tardíos de Schönberg y Beethoven.
\end{abstract}

Palabras clave: Adorno; Escuela de Darmstadt; música informal; filosofía de la música.

\begin{abstract}
This paper intends to analyze Theodor W. Adorno's critique of the compositions and compositional procedures of the Darmstadt School, considered as a development of certain dodecaphonic techniques, in order to deal with Adorno's proposal of an informal music, on the one hand, as a counterpoint and a sublation in respect to these musical developments and, on the other hand, so as to link this proposal with the ideal of freedom he had seen in free atonality aswell as with the kind of work carried out, according to his view, in Schönberg's and Beethoven's late compositional style.
\end{abstract}

Keywords: Adorno; Darmstadt School; informal music; philosophy of music.

DOI: http://dx.doi.org/10.11606/issn.2318-9800.v20i2p201-217

El niño que busca en el piano una melodía constituye el prototipo de todo verdadero componer. De un modo igualmente inseguro (...) busca el compositor lo que quizá ha estado ya ahí desde siempre y ahora él debe recuperar entre las indistintas teclas blancas y negras.

T. W. A., "Motivos"

En el capítulo "Modernidad" de Introducción a la sociología de la música, Theodor W. Adorno apunta, con referencia a las producciones más recientes de la música académica de su época, la dificultad para juzgar "si su negatividad expresa la negatividad social, y por ende la trasciende, o si meramente la imita inconsciente 
de su embrujo"1.

La experiencia negativa, es decir, el carácter crítico de la obra de arte respecto de una sociedad determinada, era para Adorno el principal aporte de la obra de arte y veía la expresión más radical de ésta en el arte moderno. Pero mientras que la producción del atonalismo libre constituyó, desde su perspectiva, el principal exponente de la negatividad moderna en el ámbito musical, otro fue su juicio respecto de los desarrollos que derivaron de este primer alejamiento de la tonalidad en las obras de Arnold Schönberg y sus discípulos.

En el marco del análisis del método dodecafónico que desarrolla en su Filosofía de la nueva música, Adorno ya había anunciado el peligro respecto de la posibilidad de que la imagen crítica de la represión de la sociedad administrada delineada por la obra musical íntegramente racionalizada se torne reproducción ideológica. Este augurio parece encontrar su cumplimiento, según los trabajos posteriores de Adorno, en las composiciones del período de post-guerra de los herederos del dodecafonismo, los músicos de la Escuela de Darmstadt. Afirmaba entonces que la obra dodecafónica tiene su costado verdadero en tanto, en una sociedad irreconciliada, niega el principio de la unidad sin fisuras que guiaba al componer clásico, pero, a su vez, es falsa siempre que se conforme acríticamente a la tendencia histórica de su propio material acomodándose sin objeciones a la falsa universalidad imperante y se agote en mero despliegue de la técnica.

Si para Adorno el progreso técnico logrado por la razón instrumental de la ciencia troca en la sociedad en fuerza opresiva, el dominio del material resultante de la progresiva racionalización de los procedimientos en arte permite lograr la realización estética en la inmanencia de la forma de una emancipación que se presente como la utopía de reconciliación de lo no-idéntico, de lo oprimido, frente a la opresión de la realidad social; la razón, entonces, en comunión con el componente mimético intrínseco al arte, explora el dominio de lo reprimido para salvarlo. Ahora bien, cuando la imaginación, en la creación artística, se somete al determinismo de la técnica y los medios se hipostasían como fines, se convierte entonces el arte en mera research, homologándose al conocimiento científico y adhiriendo, en consecuencia, al tecnocratismo. Confundiéndose con la ciencia, el serialismo integral deviene así, para Adorno, ideológico.

En el presente trabajo exploraremos, primeramente, las críticas que Adorno hará al proceder de esta escuela compositiva, que dará como resultado lo que él llamará una "nueva música envejecida”, para intentar mostrar, en segundo término, cómo la propuesta adorniana de una música informal, condensada en la publicación ampliada de la conferencia "Vers une musique informelle" representa, en este

1 ADORNO, T. W. Disonancias. Introducción a la sociología de la música. Trad. de Gabriel Menéndez Torellas. Madrid: Akal, 2009, p.376. 
sentido, un contrapunto respecto de tales tendencias, el cual, incorporándolas y superándolas, recupera para el compositor el ideal de libertad que Adorno pide al arte -y que en su filosofía de la música supo encontrar ejemplificados en el atonalismo libre así como en los estilos tardíos de Beethoven y Schönberg- al tiempo que esboza una salida para la situación musical contemporánea de la que Adorno da cuenta en sus últimos escritos.

\section{Las críticas a la Escuela de Darmstadt: nueva música envejecida}

\section{Espacialización de la música}

Las tendencias que, en Filosofía de la nueva música, Adorno empezó a observar con preocupación a propósito del dodecafonismo, ${ }^{2}$ se profundizan con la serialización de todos los parámetros compositivos que pone en obra el serialismo integral. Un primer aspecto puesto en cuestión en la crítica de Adorno es la "espacialización" de la música, resultante del estatismo de las composiciones de los músicos de la Escuela de Darmstadt, es decir, de la ausencia de la calidad dinámica que implica la manipulación de la forma en su realización en el tiempo y el rechazo, en general, del desarrollo en el sentido tradicional del concepto por parte de los compositores.

El parentesco más cercano para analizar esta tendencia se encuentra en su antecesor inmediato, el dodecafonismo. En Filosofía de la nueva música, Adorno sostiene que la omnipresencia del acorde dodecafónico que apareja la armonía complementaria, detiene el desarrollo dinámico de la composición sin resolverlo, anulando en consecuencia la experiencia musical del tiempo. Ahora bien, a la pérdida de dinamismo resultante del reemplazo de la armonía tonal por la armonía complementaria, ha de sumarse el análisis del fenómeno que ofrece Adorno en su tratamiento de la música de Stravinski presente en la segunda parte del mismo libro, música que según este aspecto podría emparentarse con la de la Escuela de Darmstadt, siendo posible trazar una suerte de línea general en la tradición musical desde la segunda mitad del siglo XIX hasta entrado el siglo XX inclinada al estatismo, en oposición al dinamismo musical de los períodos previos.

Para empezar, Adorno establece allí como antecedentes directos de Stravinski a los dos impresionistas franceses y al antagónico Wagner. La armonía afuncional de Debussy, por un lado, sustituye las fuerzas dinámicas por complejos armónicos estáticos permutables entre sí. Por otro lado, el reemplazo de la cadencia por la modalidad en el procedimiento compositivo de Ravel suprime el dinamismo connatural al desarrollo cadencial. Finalmente, se apunta en el incesante empuje dinámico wagneriano algo de ilusorio, dado que el constante crescendo acaba por no conducir a nada: la tensión

2 Para la crítica de Adorno al dodecafonismo, cf. ADORNO, T. W. Filosofía de la nueva música. Trad. de Alfredo Brotons Muñoz y Antonio Gómez Schneekloth. Madrid: Akal, 2003, pp.63-102. 
irresuelta recurre a la repetición de lo mismo. ${ }^{3}$ Según Adorno, la profundización de estas tendencias hacia lo estático desemboca, en la música de Stravinski, en una yuxtaposición de partes que disocia el continuo temporal. Autonomizados los acordes inorgánicos respecto de los complejos armónicos y anulada la conducción de la tensión hacia el reposo, sus composiciones niegan las relaciones temporales y aparecen espacializadas, como un lienzo, en la repetición de fórmulas rítmicas que deshacen el decurso temporal.

En el caso de los compositores de la Escuela de Darmstadt, existe, al considerar la totalidad de la obra, un rechazo del desarrollo lineal en el tiempo que atenta contra la concepción tradicional de la dinámica. Es aquí la concentración en el trabajo sobre la microestructura la que da por resultado, una vez más, la yuxtaposición de bloques que anulan el dinamismo de la macroestructura y se traducen en pinturas de grandes cuadros sonoros, donde la experiencia del tiempo parece escapar hacia una superficie suspendida. En obras como Atmosphères de Ligeti, Gesang der Jungelinge de Stockhausen, Diamorphoses de Xenakis o Il canto sospeso de Nono, por citar algunas, se deja escuchar claramente esta característica desde la primera audición. Asimismo, el espacio comienza a ser tratado como parámetro compositivo, como es visible en el proceder de Stockhausen en Gruppen, en lo relativo al espacio acústico, o respecto del volumen en los gráficos de Xenakis. ${ }^{4}$

Adorno reconoce, en este sentido, que la orientación generalizada hacia la superposición de bloques homofónicos hace pensar en que la espacialización constituye ya una obligación objetiva, ${ }^{5}$ encauzable con la actitud general de las artes en el siglo XX, inclinadas a borrar la división entre ellas, en este caso, en una pseudomorfosis de la música con la pintura. Sin embargo, siguiendo la distinción bergsoniana sostiene, contra la idea de un temps-espace reinante en las obras de la época, la ineluctabilidad del temps-durée en la forma musical. Al tratar al tiempo musical como a un parámetro disponible, los compositores del serialismo integral se acercan a la concepción científica de éste, aquélla mentada por el temps-espace - el tiempo cuantificado, espacialmente mesurable. Apunta entonces que esta concepción estática de la música, que implicaría la posibilidad de que lo idéntico retorne del mismo modo, se construye sobre la base de un error: en la música, en tanto arte

3 Adorno cita al respecto a Busoni: "a cada comienzo tranquilo seguía un rápido movimiento ascendente. El Wagner en esto insaciable pero no inagotable se vio en la necesidad de recurrir al expediente de, tras alcanzar un punto culminante, volver a empezar piano para enseguida crecer de nuevo". (Idem, p.165).

$4 \mathrm{Cf}$. SOLOMOS, M. «Adorno et la génération de Darmstadt: un commentaire critique». En: DUFOURT, H.; FAUQUET, J. M. (comp.). La musique depuis 1945: matériau, esthétique et perception. Bruselas: Mardaga, 1996, p.125.

5 Cf. ADORNO, T. W. "Sobre algunas relaciones entre música y pintura". En: Escritos musicales I-III. Figuras sonoras/ Quasi una fantasía/ Escritos musicales III. Trad. de A. Brotons Muñoz y A. Gómez Schneekloth. Madrid: Akal, 2006, p.639. 
que se desenvuelve en el tiempo, lo idéntico se vuelve no-idéntico en el transcurso, lo que a priori se presenta como igual deja de ser tal según su lugar en la totalidad temporal de la obra; el sonido, temporal en sí, no puede escapar a la no-identidad de la identidad, esencial al tiempo según el análisis hegeliano. Por lo tanto, como sostiene en "El envejecimiento de la nueva música", las relaciones temporales se imponen incluso contra la voluntad del compositor que intenta eludirlas. El tiempo, pues, no puede ser negado en la música inmediatamente ni puede ser indiferente en ella qué va antes y qué va después. Así, la diferencia, el momento cualitativo frente al cuantitativo, se impone a cualquier cálculo: "el equilibrio seguro que han calculado sobre el papel no se lleva a cabo", más bien "desaparece ante el único elemento del que depende artísticamente: el decurso musical del momento presente"6.

La racionalización del tiempo que implica su tratamiento como parámetro compositivo desde el procedimiento serial, en consecuencia, saca a la música de su elemento propio, que al ser capturado pierde su naturaleza abierta en tanto tempsdurée y se congela en temps-espace, como mero ser ahí en vez de ser aquello que deviene. ${ }^{7}$ La razón, en tanto fuerza de la igualación y de lo cuantitativo, parece negar, para Adorno, lo cualitativo y lo no-idéntico intrínseco a la temporalidad, tornándose entonces fatal su disponibilidad como parámetro. Esta renuncia al devenir en el interior de la forma es, desde su perspectiva, la imagen de una sociedad cuya racionalización la lleva a un estado de ahistoricidad que se diluye en lo que es y que lo adora como único posible, renunciando a todo porvenir. El tiempo se repliega en el espacio y desaparece la posibilidad del cambio. Espacializándose, la música refleja el gesto del desistir de todo progreso social siguiendo los dictámenes de la falsa racionalidad del mundo administrado.

\section{Retirada del sujeto y fetichismo del material}

Uno de los puntos fundamentales en torno a los que se concentra la crítica de Adorno lo constituye la salida del sujeto. Si los momentos concretos, la ocurrencia, el detalle, identifican para Adorno en el interior de la obra el momento subjetivo, la violencia ejercida por la totalidad con la preformación de la serie, en tanto impuesta desde arriba y con total independencia respecto de la relación de estos momentos entre sí, que ya había apuntado en sus análisis del dodecafonismo, no se ve más que profundizada por la organización total de los parámetros compositivos con el serialismo integral. En la composición serial, la totalidad no surge, según Adorno, de la relación entre los momentos monádicos mismos, sino que se sacrifican a un todo erigido por la fuerza de unas reglas alienadas y a priori que los someten, por lo

6 ADORNO, T. W. "El envejecimiento de la nueva música". En: Disonancias. Introducción a la sociología de la música, p.152.

7 Cf. ADORNO, T. W. "Música y técnica". En: Escritos musicales I-III, p.252. 
tanto, arbitrariamente, del mismo modo que en el plano social la totalidad aplasta la verdadera libertad de los individuos que se tornan meras mónadas intercambiables. Sin la tensión con lo subjetivo, en uno y otro caso, la totalidad es violencia.

Ahora bien, si, siguendo el desarrollo de Filosofía de la nueva música, mientras que todavía en el dodecafonismo -incluso en el caso más extremo que representa Webern - esta reproducción constituía para Adorno una imagen crítica de la sociedad, anulada ya completamente la libertad compositiva por la completa sumisión al método del serialismo integral, degenera en ideológica. La determinación total derivada del principio dodecafónico lleva esta primera gran exoneración del sujeto respecto de la construcción de la objetividad musical a su punto máximo. El procedimiento, entonces, termina por volverse indistinto respecto del componer mismo y la composición acaba siendo reemplazada por la preformación. Bajo la guía de la intención de extirpar todo tipo de arbitrariedad de la composición, se concluye en la eliminación completa de la libertad compositiva, de modo que con la supresión virtual del sujeto, se suprimen asimismo todos los controles que él ejercía en la constitución de la obra; en este sentido, afirma Adorno que el mismo procedimiento que desembarazaba al compositor de su tarea, "le cuesta propiamente el pellejo"8.

Puesto que la necesidad de racionalización se le enfrenta desde fuera al compositor, el orden, en lugar de seguirse de los acontecimientos musicales de la obra misma, se impone por medio de la violencia. Los compositores capitulan, pues, ante los medios con los que deben trabajar sin realmente componer con ellos y limitándose a tareas de corrección. ${ }^{9} \mathrm{El}$ acto de componer, en consecuencia, es sustituido por el cálculo objetivo de la disposición del material y, anulado el momento subjetivo, la objetividad se torna meramente una apariencia que decreta la preformación sistemática ${ }^{10}$ mientras el compositor termina por adaptarse a la heteronomía, tornándose la obra reproducción acrítica de las tendencias sociales regresivas de depotenciación del individuo.

Correlativamente a esta retirada del sujeto, el método y el material se ven convertidos en fetiche. Por un lado, se busca una confrontación directa con el material y se lo adora en tanto aparentemente puro como a un ídolo. Contra esto, Adorno sostiene que no hay posibilidad de dar con un material que no esté ya subjetivamente mediado; no hay tal cosa como un material puro, libre de

8 ADORNO, T. W. "Dificultades para componer música". En: Impromptus. Barcelona: Laia, 1985, p.128.

9 Solomos apunta como ejemplos, a este respecto, las obras de la segunda producción de Xenakis, en donde aparece marcadamente la presencia, de un lado, de sistemas muy rígidos y, de otro, la corrección por parte del compositor apelando al bricolage. (Cf. SOLOMOS, M. «Adorno et la génération de Darmstadt: un commentaire critique». En: DUFOURT, H.; FAUQUET, J. M. (comp.). La musique depuis 1945: matériau, esthétique et perception, p.129).

10 Cf. ADORNO, T. W. "El envejecimiento de la nueva música". En: a la sociología de la música, pp.150-1. 
contaminación del espíritu. Para Adorno, el material es "espíritu sedimentado", subjetividad cristalizada históricamente que olvida en el transcurso su calidad de subjetiva y, en este sentido, el sonido, primero en el ámbito de lo acústico, no es en la música sino una abstracción. Consecuentemente, el compositor, queriendo acceder a la objetividad olvidado de la mediación, termina acomodándose a los dictados de la sociedad acríticamente. Por otro lado, al agotarse la composición en la preformación, se extrema el fetichismo técnico que ya despuntaba junto con el componer dodecafónico. En el afán de buscar la objetividad por una ficticia retirada del sujeto, por el rigor científico-matemático de una obra técnicamente prístina, se sacrifica el sentido musical en el altar de la técnica y el ideal de la corrección se cumple a costa del contenido de verdad. La unilateralidad de la objetivación que quiere pasar por alto el sujeto desemboca en un subjetivismo extremo, por el que el dominio de la naturaleza que resulta de la racionalización de la composición no hace sino adorar ideológicamente al resultado de manipulaciones históricas como a un ser en si $^{11} \mathrm{y}$ los medios, finalmente, se erigen en fin.

\section{Pérdida del sentido musical}

Desaparecido el sujeto de la obra, reemplazada la composición por la preformación y fetichizados la técnica y el material, la obra serial se vacía de sentido. El sentido musical constituye, para Adorno, lo espiritual en la obra, la trascendencia en que la inmanencia se convierte, aquello que va más allá de lo sensible mismo pero que sólo se produce desde ello, desde la coherencia formal de la composición musical. ${ }^{12}$ Se construye entonces sobre la relación dialéctica entre la expresión y la construcción. Si desde su concepción tradicional el sentido se relacionaba en la música con el lenguaje tonal y algunas categorías a él vinculadas como las de antecedente y consecuente, enunciado y mediación e ideas primarias y secundarias, según Adorno, el arte de vanguardia de las primeras décadas del siglo XX, rebelado contra la apariencia y la falsa totalidad en protesta contra la realidad irreconciliada, hace del sinsentido su sentido y de la falta de coherencia, su coherencia. La caída del lenguaje tonal significó la pérdida de evidencia del sentido musical dada la privación de la solidez universal que éste le aportaba, por lo que, en adelante, los compositores deben encargarse de infundir a la obra el sentido que antes le aseguraba el espíritu objetivo.

Ahora bien, para Adorno, mientras que en las obras revolucionarias el compositor asume la tarea de construcción del sentido desde el sinsentido, en las obras del serialismo integral, exonerado el sujeto por la preformación, se asume la falta de sentido meramente como programa y la organización de los medios

11 Cf. ADORNO, T. W. "Música y técnica". En: Escritos musicales I-III, p.239.

12 Cf. ADORNO, T. W. "Criterios de la nueva música”. En: Escritos musicales I-III, pp.193-5. 
sustituye la finalidad negada. ${ }^{13}$ Como lo advierte Anne Boissière, apoyándose sobre la idea de la existencia de una dialéctica entre el material y su puesta en forma que considera como necesaria en las obras de arte, Adorno objeta la ausencia total de articulación de material que pretende hacer de la manipulación de éste a través de los procedimientos contexto de sentido. ${ }^{14}$ La cosificación que se sigue de la pérdida de la fuerza de la realización viva ejecutada por el oído del compositor troca el sentido musical por el mero cálculo, haciendo de la conexión algo irreconocible en la audición.

En “El envejecimiento de la nueva música”, Adorno apunta que el arte se parece a la ciencia en el hecho de hacer uso de la técnica, pero que mientras que la finalidad de esa utilización es en el caso de la ciencia, como señalamos más arriba, la dominación de la naturaleza, en lo que respecta al arte se trata de la producción de una estructura con sentido que depende sólo de la composición misma; el arte se constituye, por lo tanto, en un movimiento reflejo de la hegemonía de la ciencia. ${ }^{15}$ Sin embargo, cuando se vacía de un sentido propio y no tiene algo que transparentar -ese algo que va más allá de lo sensible desde lo sensible mismo-, se confunde con la ciencia para salvarse del mundo desencantado que no le da sitio y se convierte en mero bricolage, impotente en lo real y estéticamente estéril. La obra se agota, en consecuencia, en un progreso de los medios que carece de meta y, negando su sentido, niega su razón de ser:

Lo mismo que en una comunidad totalmente dominada por la administración todos los elementos engranan entre sí, lo mismo que en ella todos funcionan para todos sin fisuras, pero ninguno sabe ya para qué funciona el conjunto; lo mismo que a ninguno se le devuelve lo que bajo la coacción de la identidad universal de todos cedió de su esencia no-idéntica, así a los impulsos individuales no se les devuelve nada de lo que los empuja al todo. ${ }^{16}$

Llegamos con esto al nudo de la crítica de Adorno al serialismo integral. Dada la tensión subjetiva con la que se opera sobre el material, la eliminación del sentido significa en la obra de vanguardia una protesta contra la realidad: la falta de sentido se erige como la expresión más potente de la catástrofe objetiva. Negativa, la obra sacrifica su coherencia y su apariencia y, con ellas, pone en peligro su propia existencia para expresar el sufrimiento, lo no-idéntico oprimido por la totalidad. Es el "llanto"

13 Cf. ADORNO, T. W. "El envejecimiento de la nueva música". En: Disonancias. Introducción a la sociología de la música, pp.156-7.

$14 \mathrm{Cf}$. BOISSIĖRE, A. «Le positivisme en question: les affinités d'une double querelle chez Adorno». En: DUFOURT, H.; FAUQUET, J. M. La musique depuis 1945: matériau, esthétique et perception. pp.142-3.

15 Cf. ADORNO, T. W. "El envejecimiento de la nueva música”. En: a la sociología de la música, pp.157-8.

16 ADORNO, T. W. "Música y técnica”. En: Disonancias. Introducción Escritos musicales I-III, p.238. 
de la realidad irreconciliada. Pero si incluso en el extremo endurecimiento de la obra dodecafónica el material era introducido en plena tensión subjetiva, con "temor y temblor"17, en las obras del serialismo integral la tensión vanguardista se neutraliza en estilo. El material antes tenso, las disonancias, los contrastes, se reproducen académicamente, sin poner nada en juego. Perdida la tensión interna, la obra deja de denunciar un estado de cosas, pierde su fibra crítica y se convierte en un mero juego matemático de resolución de problemas indiferente a los "gritos" de todo lo sometido.

En este sentido, como afirma Dufourt, al confundir la investigación tecnológica con la elaboración estética, igualándose a la ciencia, la música del serialismo integral reproduce la racionalidad instrumental del tecnocratismo reinante y en lugar de poner la técnica al servicio de lo oprimido y conciliar la racionalidad con lo no-idéntico, se hace cómplice del mundo administrado y degenera en ideológica, erigiendo "el mundo de Beckett en imagen de un provenir radiante"18. La obra de vanguardia lleva su tensión interna al máximo y renuncia al sentido para no renunciar a su contenido de verdad, al registro de las contradicciones de la realidad objetiva; las composiciones de la Escuela de Darmstadt renuncian al contenido de verdad y degeneran en un sinsentido objetivamente estéril. Finalmente, perdida la tensión interna y con ella la fibra crítica, aquello que alguna vez fue negativo se neutraliza, tornándose afirmativo.

Esta afirmatividad producto de la merma de tensión es la que hace hablar a Adorno de un envejecimiento de la nueva música, cuya causa antropológica la encuentra en una juventud que tras ver el horror perpetrado de la guerra, el exterminio y el totalitarismo, se aparta por completo de la realidad empírica y de cualquier rastro de ella en la expresión -como si el terror se hubiera vuelto ya demasiado grande para poder ser todavía expresado- y cuya parálisis es síntoma del mundo administrado en donde se paraliza toda iniciativa libre. Según Adorno, si aún la composición dodecafónica, frente al pánico del Estado integral, se deshumanizaba hasta sobrepasar lo inhumano del mundo para salvar lo humano, ${ }^{19}$ la obra del serialismo integral, congelada por el terror y alejada de su expresión, peligra de no tener ya nada en común con lo humano $\mathrm{y}$, olvidado su contenido humano, se convierte en fetiche técnico.

Parafraseando a Kierkegaard, en alusión a este envejecimiento de lo nuevo que reconoce en el serialismo integral, afirma Adorno: “allí donde se abría una vez el terrible abismo, está tendido ahora un puente de ferrocarril desde el cual los viajeros

17 ADORNO, T. W. "El envejecimiento de la nueva música". En: Disonancias. Introducción a la sociología de la música, p.148.

18 DUFOURT, H. «Élites et programmes: le compromis de la musique avancée depuis 1945». En: AA. VV. Actes du colloque "La musique et les pouvoirs", Mouvement Janacek, n² 26-27, 1995, p.113.

19 Cf ADORNO, T. W. Filosofía de la nueva música, p.118. 
miran placenteramente las profundidades"20. Neutralizada, ajena a la tensión y al sentido, alejada de aquel impulso perturbado que movía a la música de la generación previa, afirmativa, la obra de la nueva música envejecida se resigna y pierde el núcleo crítico que le otorga su dignidad al arte. Nadie siente ya en ella una exigencia comprometida con la verdad.

\section{2. "Dire cela, sans savoir quoi": el retorno a la libertad de la "musique informelle"}

Como contrapartida del serialismo integral y contra la reificación de esta música neutralizada que se abandona a la técnica sin componer y reproduce el esquema de sumisión del individuo a la totalidad social, Adorno desarrolla la idea de una "musique informelle". ${ }^{21}$ Siguiendo el camino trazado por las composiciones tardías de Beethoven y Schönberg y retomando el sueño de libertad del expresionismo, esta concepción de la música que esboza intentará conducir la racionalización llevada a cabo por el dodecafonismo y la Escuela de Darmstadt a buen puerto, recuperando la olvidada porción utópica de la música.

La propuesta de la música informal aparece mencionada -a veces explícitamente; otras, sólo en la sugerencia de los lineamientos que la caracterizanen varias oportunidades en los escritos musicales de las dos últimas décadas de la vida de Adorno. Pero es en la conferencia dictada en Darmstadt en 1961 y luego revisada y ampliada para su publicación, "Vers une musique informelle", en donde se la desarrolla más sistemáticamente. De acuerdo con la dicotomía planteada sobre el final de "Dificultades para componer música”, según la cual la música de la época se encamina o hacia fetichismo del material y del método de las composiciones de la Escuela de Darmstadt o a la pura aleatoriedad de la música de Cage y sus seguidores, ésta se presentaría como una tercera opción que asume la mediación subjetiva, una frente a lo que allí parece plantearse como un callejón sin salida.

Considerada la situación descripta en los párrafos anteriores dedicados a la crítica del serialismo integral, el punto de partida de la "musique informelle" es la necesidad de autorreflexión de la música, el volverse de la cosa sobre sí misma que ya en otra oportunidad había planteado como único camino frente al envejecimiento de la nueva música. ${ }^{22}$ Desde este punto de vista, si la crítica a las composiciones de la Escuela de Darmstadt, así como al dodecafonismo, había mostrado la violencia que implica el sometimiento a legalidades exteriores -en lo relativo a la serie en el

20 ADORNO, T. W. "El envejecimiento de la nueva música". En: Disonancias. Introducción a la sociología de la música, p.146.

21 Acuñada la expresión en el idioma francés, Adorno dice elegirlo para la denominación de su propuesta como gesto hacia la tierra de las vanguardias y de la manifestación civil. (Cf. ADORNO,

T. W. «Vers une musique informelle». En: Escritos musicales I-III, p.506).

22 Cf. ADORNO, T. W. "Música y técnica". En: Escritos musicales I-III, pp.244-5. 
caso del dodecafonismo y de la predeterminación de todos los parámetros en el del serialismo integral- en tanto en tales circustancias la totalidad no se deduce de los momentos individuales de la obra misma sino que le llega desde arriba, reproduciendo la falsa racionalidad que Adorno encuentra en el mundo administrado, la "musique informelle" es definida, desde un primer acercamiento, como una música "que se constituye de una manera objetivamente obligatoria en el fenómeno, libre de legalidades exteriores"23. Esto implica, por un lado, la asunción de la experiencia nominalista de las primeras décadas del siglo XX por la que ya no se tolera un lenguaje universal, pero también la toma de conciencia del nominalismo sobre la obligación de ser objetivo; la objetividad, en consecuencia, ni debe abandonarse ni debe intentar ser impuesta desde fuera, sino que tiene que arraigar en la obra misma: sólo desde la particularización puede construirse lo legítimamente universal. ${ }^{24}$ Una vez más, se sostiene que lo universal debe surgir desde abajo en lugar de ser violentado desde arriba y, por lo tanto, tiene que reaparecer en la obra, es decir, construirse desde las necesidades que ella plantea. En este sentido, Adorno se pregunta a qué responde la necesidad de un orden exterior que luego de la libertad hacia la que abrió el camino el atonalismo libre significó la nueva sistematización de la técnica serial. Siendo que la cosa misma no proyecta tal necesidad, sino que cada composición admite, de hecho, infinitas posibilidades de organización dentro de ella misma, Adorno la adjudica a un factor ideológico-sociológico, a una necesidad de seguridad ajena a lo propiamente musical y más bien debida a la mala conciencia de la libertad en la que la falta de libertad vive. Perdiendo el miedo al caos, la música informal se postula como una libertad sin concesiones ${ }^{25}$ que, sin volver atrás el curso de la historia posterior a los que Adorno considera los años de la libertad del atonalismo libre y sin entregarse al caos, como pretenderían quienes sostienen la imprescindibilidad de un ordenamiento exterior, retoma la búsqueda de la construcción de la objetividad únicamente desde las obligaciones inmanentes de la obra.

\section{Superación de la tendencia espacializadora en un nuevo dinamismo. Los modelos} de Mahler y Berg

En relación con esta última cuestión, Adorno apunta como primera necesidad la búsqueda de una recuperación del principio dinámico contra la tendencia generalizada al estatismo en la música. Como ya se ha señalado, la falta de relación entre los momentos individuales a la que conduce la imposición de la totalidad desde procedimientos externos a lo específico de la obra, da como resultado una yuxtaposición de partes inconexas que liquida el principio de dinamismo, guía de

23 ADORNO, T. W. «Vers une musique informelle». En: Escritos musicales I-III, p.506.

24 Cf. ADORNO, T. W. "Criterios de la nueva música”. En: Escritos musicales I-III, pp.179-81.

25 Cf. ADORNO, T. W. «Vers une musique informelle». En: Escritos musicales I-III, p.508. 
la música motívico-temática -procedimiento ejemplificado por excelencia en las composiciones del segundo período de Beethoven. Al rebelarse la nueva música contra la apariencia, se deshace del dinamismo ficticio que es connatural a la música en tanto inmovilizada por la escritura y, buscando conservar su autenticidad, se vuelve estática. Sin embargo, señala Adorno, ésta no es sino una negación abstracta del dinamismo del componer motívico-temático, por lo que hace falta integrarlo, todavía, a los resultados musicales. La música serial, en su búsqueda de objetividad, pretendía aislar el sonido, lo inmediato. Asume, en este sentido, una función crítica respecto de las intenciones del sujeto en tanto meramente insertas; sin embargo, no es un momento positivo en sí sino que para serlo necesita de configuraciones que no se extraen de él. La mediación subjetiva que permite las relaciones entre estas instancias abstractas es, como hemos repasado, inevitable -de ahí que se hable de una abstracción: el sonido es siempre en relación con otros sonidos. ${ }^{26} \mathrm{La}$ música informal buscará recuperar el concepto de relación, que asume sobre sí la composición motívico-temática así como el momento crítico que ejerce el serialismo contra las intenciones del sujeto y lo ficticio del dinamismo, dominando el vínculo en la forma temporal al absorber y controlar mediante el oído compositivo aquello que va más allá de cada nota individual. ${ }^{27}$

Es significativo a este respecto, como señala Anne Boissière, ${ }^{28}$ aquello que Adorno rescata en sus análisis sobre Mahler y Berg, paradigmas de un dinamismo que parte del trabajo sobre los momentos singulares. Abandonada a los impulsos individuales, la obra de Mahler se construye, según Adorno, desde abajo hacia arriba en lugar de responder a un diseño abstracto $y$, contra la ilusión de una totalidad que establecería un sentido inexistente en la sociedad real, la totalidad cristaliza a través de los detalles al mismo tiempo en que se deshace. ${ }^{29}$ En su dinamismo constitutivo, la obra de Mahler representa una crítica a la variación clásica puesto que si bien en ella lo otro surge de lo mismo, no se deja deducir de éste; el desarrollo, de este modo, no está subordinado a ninguna posición inicial sino que todo se dirige irresistiblemente hacia adelante. El dinamismo, entonces, lejos de resultar en una unidad sin fisuras, tiende a lo informe, se presenta como una organización extrema de algo desorganizado, de algo que en su total formación quiere disolverse en lo amorfo. ${ }^{30}$

26 Por esto Adorno prefiere hablar de figura -concepto que ya comporta la idea de la relación- en lugar de utlizar el término "sonido" al referirse a lo primario en el ámbito de la música. (Cf. Idem, p.529).

27 Cf. Idem, p.532.

$28 \mathrm{Cf}$. BOISSIÈRE, A. «La conception bergsonienne du temps dans l'esthétique musicale d'Adorno». Actualités d'Adorno, Rue Descartes. Collége International de Philosophie, n 23, marzo 1999, pp.85-98.

29 Cf. ADORNO, T. W. "Mahler". En: Escritos musicales I-III, pp.334-345.

30 Cf. BOISSIÈRE, A. «La conception bergsonienne du temps dans l'esthétique musicale d'Adorno». 
La microtécnica de Berg, en la misma dirección, construye la forma de modo dialéctico a través de un proceder minuciosamente focalizado en el detalle. Modificando el trabajo temático clásico, desaparecen los temas estáticos deshaciéndose en una variación constante en donde cada detalle toma sentido de su relación con la totalidad y ésta se legitima sólo desde el impulso de los detalles. Como transición permanente, una vez más, la extrema organización tiende a la desorganización "en un proceso compositivo disolvente y a la vez vinculante de los más mínimos elementos con la construcción" 31 . Si lo individual en estética no puede ya lograr ninguna objetivación incólumne desde sí mismo y si toda objetividad que se le impone desde afuera resulta ajena, las composiciones de Berg y Mahler absorben este antagonismo y son como el tapiz de Penélope, destejiéndose por el mismo movimiento en que se tejen. Sin postular, por lo tanto, una totalidad sin fisuras que no podría ser desde la perspectiva de Adorno más que ideológica, empujan la obra desde el momento individual en constante variación y constituyen un ejemplo de recuperación, modificado respecto del motívico-temático, del dinamismo perdido.

\section{Organicidad reformulada y recuperación del lugar del sujeto y de la dialéctica interna}

Frente al mecanicismo de la fe en el material y la organización total en donde el pasaje de un momento concreto a otro se presentaba como una yuxtaposición de partes sin nexo, ligadas por lo tanto sólo de manera contingente, Adorno señala la necesidad de retomar, sin caer en el ideal ya irrecuperable de la obra redonda, algo del programa orgánico que plantea la tendencia a su conexión en pos de una unidad en devenir entre el todo y la parte -aquella organización finalista que asemeja a la obra de arte a los organismos. El en sí de la obra de arte no puede desechar esa parte de sí misma que la hace ser para nosotros. Como en Mahler y Berg, desde la transformación de lo compuesto mismo la fuerza temática, aun renunciando a sus medios habituales, ha de ser la encargada de superar el estatismo en la música y de restituirle su carácter propiamente temporal y, con ello, algo de su organicidad. La música informal, por lo tanto, buscará establecer las relaciones entre los momentos que permitan construir algo orgánico, si bien, frente a la deshumanización de la realidad objetiva, no puede reducirse a la imitación de una vida orgánica que significaría una reificación. En "La forma de la nueva música” rescatará a este respecto la categoría de "nudo", que intenta mentar la idea del logro de una sucesión desde las relaciones intracompositivas en lugar de a través de técnicas prestadas de las artes pictóricas y que depende plenamente de los acontecimientos monádicos de la pieza individual;

Actualités d'Adorno, Rue Descartes. Collége International de Philosophie, n 23, marzo 1999, p. 88.

31 ADORNO, T. W. “Berg”. En: . Escritos musicales I-III, p. 94. 
al crear "nudos sin dramaturgia”, el decurso tampoco depende de los excesos de una voluntad exterior sino que resulta de las exigencias mismas de la pieza. ${ }^{32}$

Ahora bien, esta organización necesita de lo no mecánico, del momento de la vida: la organicidad de la obra reclama al sujeto. En oposición a la tendencia de pérdida de la tensión subjetiva y a la exoneración del sujeto y para recuperar el sentido y la objetividad musicales, el ideal de la "musique informelle" plantea la necesidad de una relación dialéctica entre subjetividad y ley, entre la expresión del sujeto y la construcción. No puede pretenderse la sustitución de ésta por un orden musical del ser cuya existencia, como se ha mostrado, es imposible para Adorno, puesto que los materiales son lo que son solamente en su relación con el sujeto social que trabaja con ellos. Por otra parte, dado que no existe tal cosa como una inmediatez en el plano musical, tampoco puede pretenderse la acción directa que intentan las tendencias del action composing y otras clases de experiencias aleatorias a las que recurren en sus composiciones artistas como John Cage para escapar a la reificación de la racionalización de la obra integral.

En este sentido, afirma Adorno que la posibilidad de escapar del dominio sobre la naturaleza -no sólo en la música sino también en el arte en general y en concordancia con la teoría crítica- sólo se consigue por el dominio subjetivo del material y de la técnica, en una dialéctica entre sujeto y objeto que redima a lo noidéntico frente a la opresión ejercida por la igualación totalizadora de la razón. Por lo tanto, es haciéndose dueña de sí que la música logra la libertad de todo mandato. Sin la compulsión dictada por la técnica y el material, por un lado, y sin la añadidura de intenciones subjetivas, por otro, ambas instancias ajenas a la cosa misma, el oído compositivo reasume su rol en la composición y se entrega autocríticamente a su tarea hasta apropiarse de las tendencias del material. Aboliendo la unilateralidad, ni impone sus intenciones ni se amolda acríticamente a los dictados de lo colectivo del idioma y oye en su tratamiento sensible aquello en que el material se ha convertido. En su dominio de éste no infunde intenciones arbitrarias, pero sus actos continúan siendo los del oído espontáneo. Atento al material e inmerso en los momentos idiomáticos, el oído sigue a la música adonde ella quiere ir. Adorno se refiere a esta inmersión crítica del oído especulativo por la que éste se deja conducir por la música como "sentido formal", ${ }^{33}$ única forma de dar con una objetividad auténtica, construida desde el sujeto en lugar de sobre él.

La mediación subjetiva regresa, en consecuencia, en tanto crítica del contexto técnico, incorporando y superando la experiencia del serialismo sin caer presa del fetichismo del procedimiento. La tensión subjetiva es así llevada al máximo pero solamente desde el trabajo sobre el material.

32 Cf. ADORNO, T. W. "La forma en la nueva música". En: Escritos musicales I-III, pp.630-1.

33 Cf. Idem, pp.635-6. 


\section{Retorno del sentido, la apariencia y la libertad compositiva}

Por otra parte, al devolver la música informal su lugar en la obra al sujeto, vuelve a entrar en escena la tarea compositiva antes abandonada a la corrección de lo preformado y la articulación de la forma viva permite recuperar ese más allá de la inmanencia postulado desde la inmanencia. Consecuentemente, se reinstaura el sentido musical y con él la apariencia, de los que la creación artística no puede escaparse:

En una musique informelle, cabría superar positivamente el hoy deformado momento de la racionalización. Sólo lo totalmente articulado desde el punto de vista artístico es la imagen de algo no mutilado y por tanto de la libertad. ${ }^{34}$

Reasumida la relación dialéctica, se recobra la posibilidad de reconciliación que da a la música su parte de utopía y le devuelve su razón de ser en la teoría crítica, en donde el arte es el lenguaje no significativo de lo oprimido y reprimido, de lo noidéntico, de lo singular.

Contra la opresión de un mundo en el que la expresión particular es acallada en una falsa totalidad, la "musique informelle" retoma la ruptura con la coerción idiomática señalada por el atonalismo libre como promesa de una humanidad liberada. Pero si la reconciliación en el interior de la forma, a modo de lo que encontraba Adorno que sucedía en las composiciones del segundo Beethoven, no puede ser sino ideológica en una sociedad irreconciliada, los modelos para esta música serán las obras tardías de Beethoven y de Schönberg, los dos compositores más paradigmáticos para la filosofía de la música adorniana. ${ }^{35} \mathrm{El}$ dominio del material del compositor maduro marca el rumbo a seguir para la música informal. Como Beethoven supo hacer hablar a las convenciones del idioma tonal y Schönberg a las series y ambos, en el ocaso de sus vidas, lograron esta expresión refractaria, protegida de la reificación, a través del paisaje objetivo, Adorno augura para la música, con su propuesta, la posibilidad de un sentido musical construido desde la inmersión compositiva en el material que dejaron el dodecafonismo y el serialismo integral, renunciando, en este movimiento, al sentido en tanto una proyección meramente subjetiva así como a la falsa seguridad de la necesidad heterónoma de una legalidad exterior. Al igual que los maestros tardíos logran la expresión desde la objetividad sometidos únicamente a la regla de la propia imaginación, en la música informal el oído crítico ha de

34 ADORNO, T. W. «Vers une musique informelle». En: Escritos musicales I-III, p.546.

35 Para el análisis de Adorno acerca del estilo tardío de Beethoven y la caracterización adorniana de "lo tardío", cf. ADORNO, T.W. "El estilo de madurez en Beethoven". En: . Reacción y progreso y otros ensayos musicales. Trad. de José Casanovas. Barcelona: Tusquets, 1984. También SAID, E. "Adorno como lo tardío". En: Bull, M. (comp.). La Teoría del Apocalipsis y los fines del mundo. México: FCE, 1998. En lo referido al estilo tardío de Schönberg, cf. ADORNO, T. W. Filosofía de la nueva música, pp.105-114. 
integrar la experiencia del serialismo desde la espontaneidad de la composición que se deja guiar por la cosa misma y logra escuchar las determinaciones de ésta como sus propias intenciones. Iluminando al material en su articulación formal, lo depura de la sucia capa tradicional y se libera de la compulsión de los restos del idioma tonal tanto como de aquella de las técnicas seriales.

Como el niño que se sienta delante del teclado del piano y decide entre todas sus teclas con cuáles trazar la melodía, el compositor, desde el pleno dominio del material pero sin recurrir a leyes ajenas al trabajo inmanente, entreteje las conexiones de la forma. Dijo una vez Adorno a propósito de la nueva música:

[lo que] tiene de irresoluble y, en su horizonte abierto, al mismo tiempo de felicidad, consiste en el hecho de que sin ninguna clase de pautas impuestas desde fuera debe sin cesar decidir concluyentemente, como con los ojos cerrados, sobre la corrección o lo falso de cada pasaje, de cada nota [...]. ${ }^{36}$

Asumiendo el lugar que tiene en la dialéctica la negación positiva, la "musique informelle" de Adorno postula la composición como proceso de permanente crítica que, siguiendo las líneas de El innombrable, dice sin saber qué y recobra para la humanidad en la música la utopía de libertad incumplida en el mundo que despuntó con el sueño del libre atonalismo a comienzos del siglo XX.

\section{Referencias}

ADORNO, T. W. Gesammelte Schriften. Frankfurt am Main: Suhrkamp, 1990.

. Teoría estética. Trad. de F. Riaza y F. Pérez Gutiérrez. Madrid: Taurus, 1971.

- Reacción y progreso y otros ensayos musicales. Trad. de José Casanovas. Barcelona: Tusquets, 1984.

. “Dificultades". En: - Impromptus. Serie de artículos musicales.

Trad. Andrés Sánchez Pascual. Barcelona: Laia, 1985.

- Mahler: una fisiognómica musical. Trad. A. Sánchez Pascual. Barcelona: Península, 1999.

- Dialéctica negativa. Trad. de Jerónimo M. Ripalda. Madrid: Editora Nacional, 2002.

- Beethoven. Filosofía de la música, trad. de Alfredo Brotons Muñoz,

Barcelona: Akal, 2003.

. Filosofía de la nueva música. Trad. de A. Brotons Muñoz y A. Gómez

36 ADORNO, T. W. "La función del contrapunto en la nueva música”. En: I-III, p. 171. Escritos musicales 
Música envejecida y retorno a la libertad. Las críticas a la Escuela de Darmstadt ...

Schneekloth. Madrid: Akal, 2003.

Disonancias. Introducción a la sociología de la música. Trad. De Gabriel Menéndez Torellas. Madrid: Akal, 2009, p. 376.

Escritos musicales I-III. Figuras sonoras/ Quasi una fantasía/ Escritos

musicales III. Trad. de A. Brotons Muñoz y A. Gómez Schneekloth. Madrid: Akal, 2006.

- Escritos musicales V. Trad. de A. Brotons Muñoz y A. Gómez Schneekloth. Madrid: Akal, 2011.

BOISSIÈRE, A. «La conception bergsonienne du temps dans l'esthétique musicale d'Adorno». En: Actualités d'Adorno, Rue Descartes. Collége International de Philosophie, $\mathrm{n}^{\circ} 23$, marzo 1999, pp.85-98.

BOULEZ, P. “Formas”. En: - Puntos de Referencia. Barcelona : Gedisa , 1984, pp.74-80.

DUFOURT, H. «Élites et programmes: le compromis de la musique avancée depuis 1945». En: AA. VV. Actes du colloque "La musique et les pouvoirs", Mouvement Janacek, $\mathrm{n}^{\circ} 26-27,1995$, pp.109-13.

DUFOURT, H.; FAUQUET, J.M. (comp.). La musique depuis 1945: Matériau, esthétique et perception. Bruselas: Mardaga, 1996.

KALTENECKER, M. «La dialectique égyptienne». En: Olive, J. P (dir.). Expérience et fragment dans l'esthétique musicale d'Adorno. París: L'Hamattan, 2004.

ROCHLITZ, R. Language for One, Language for All: Adorno and Modernism. Perspectives of New Music, vol. 27 n², verano 1989.

SAID, E. Adorno como lo tardío”. En: Bull, M. (comp.). La Teoría del Apocalipsis y los fines del mundo. México: FCE, 1998.

SCHÖNBERG, A. “La composición con doce sonidos”. En: . El estilo y la idea. Madrid: Taurus, 1963.

STOCKHAUSEN, K. ...Comment passe le temps.... Contrechamps, n9 1988.

WILLIAMS, A. Adorno and the Semantics of Modernism. Perspectives of New Music, vol. $37 \mathrm{n}^{\circ} 2$, verano 1999.

ZURLETTI, S. «Le concept de matériau musical chez Th. W. Adorno». En: Olive, J. P. (dir.). Expérience et fragment dans l'esthétique musicale d'Adorno. París: L'Hamattan, 2004. 